\title{
Fluid and Electrolyte Transport by Cultured Human Airway Epithelia
}

\author{
Jeffrey J. Smith and Michael J. Welsh \\ Departments of Pediatrics, Internal Medicine, and Physiology and Biophysics, Howard Hughes Medical Institute, \\ University of Iowa College of Medicine, Iowa City, Iowa 52242
}

\begin{abstract}
An understanding of the fluid and electrolyte transport properties of any epithelium requires knowledge of the direction, rate, and regulation of fluid transport and the composition of the fluid. Although human airway epithelia likely play a key role in controlling the quantity and composition of the respiratory tract fluid, evidence for such a role is not available. To obtain such knowledge, we measured fluid and electrolyte transport by cultured human nasal epithelia. Under basal conditions we found that epithelia absorbed $\mathrm{Na}^{+}$and fluid; both processes were inhibited by addition of amiloride to the mucosal surface. These data suggest that active $\mathrm{Na}^{+}$absorption is responsible for fluid absorption. Interestingly, $\mathrm{Na}^{+}$absorption was not accompanied by the net absorption of $\mathrm{Cl}^{-}$; some other anion accompanied $\mathrm{Na}^{+}$. The combination of cAMP agonists and mucosal amiloride stimulated the secretion of $\mathrm{NaCl}$-rich fluid. But surprisingly, the response to CAMP agonists in the absence of amiloride showed substantial intersubject variability: cAMP stimulated fluid secretion across some epithelia, for others, cAMP stimulated fluid absorption. The explanation for the differences in response is uncertain, but we speculate that the magnitude of apical membrane $\mathrm{Na}^{+}$conductance may modulate the direction of fluid transport in response to cAMP. We also found that airway epithelia secrete $\mathrm{H}^{+}$and absorb $\mathrm{K}^{+}$under basal conditions; both processes were inhibited by CAMP agonists. Because the $\mathrm{H}^{+} / \mathrm{K}^{+}$-ATPase inhibitor, $\mathrm{SCH} 28080$, inhibited $\mathrm{K}^{+}$absorption, an apical membrane $\mathrm{H}^{+} / \mathrm{K}^{+}$-ATPase may be at least partly responsible for $\mathrm{K}^{+}$and $\mathrm{H}^{+}$transport. However, $\mathrm{H}^{+} / \mathrm{K}^{+}$exchange could not entirely account for the luminal acidification. The finding that cAMP agonists inhibited luminal acidification may be explained by the recent finding that $\mathrm{CAMP}$ increases apical $\mathrm{HCO}_{3}^{-}$conductance. These results provide new insights into how the intact airway epithelium may modify the composition of the respiratory tract fluid. $(J$. Clin. Invest. 1993.91:1590-1597.) Key words: fluid transport • airway surface fluid $\bullet$ airway liquid $\bullet \mathrm{Na}^{+}$absorption $\bullet \mathrm{Cl}^{-}$secretion $\bullet \mathrm{K}^{+}$absorption $\bullet \mathrm{H}^{+}$secretion $\bullet \mathbf{p H} \cdot$ anion gap $\bullet$ lactate
\end{abstract}

\section{Introduction}

Epithelia form a barrier that separates luminal from interstitial compartments. By secreting or absorbing solutes, they transport fluid across the epithelium and thereby modify the quan-

\section{Address correspondence to J. J. Smith, Department of Pediatrics, Uni- versity of Iowa College of Medicine, Iowa City, IA 52242-1083. \\ Received for publication 8 July 1992 and in revised form 29 Sep- tember 1992.}

J. Clin. Invest.

(c) The American Society for Clinical Investigation, Inc.

0021-9738/93/04/1590/08 $\$ 2.00$

Volume 91, April 1993, 1590-1597 tity and composition of the fluid in the luminal compartment. In addition, epithelia respond to a variety of hormones, autocoids, and neurotransmitters with a change in the rate of transepithelial fluid transport. Knowledge of the direction, rate, and regulation of fluid transport and the composition of the fluid on the luminal surface of an epithelium is central to understanding the function of that epithelium. Unfortunately, such knowledge is quite limited for airway epithelia. On the one hand, a number of studies have measured transepithelial electrolyte transport by the airway epithelia of several species (for review see reference 1 ). In addition, some of the individual ion transport processes have been studied in molecular detail. But on the other hand, our current knowledge of transepithelial fluid transport, its regulation, and its composition is clearly inadequate to understand the function of the airway epithelium.

The airway epithelium is covered by a blanket of mucus that traps inhaled particulate materials (2). Between this mucus blanket and the epithelium lies a thin, aqueous sublayer of fluid. From the epithelial surface, cilia project into the fluid so the tips of cilia make contact with the mucus blanket. The coordinate function of the mucus, fluid layer, and cilia is to propel mucus toward the oropharynx (mucociliary clearance) (3), thereby providing an important pulmonary defense mechanism. Electrolyte transport by airway epithelia is thought to be important for controlling the quantity and composition of the respiratory tract fluid. This notion is best supported by the observation that pulmonary disease occurs in patients with cystic fibrosis (CF), ${ }^{1}$ a genetic disease characterized by defective $\mathrm{Cl}^{-}$secretion and enhanced $\mathrm{Na}^{+}$absorption across airway epithelia (for review see reference 4 ).

The paucity of knowledge of the respiratory tract fluid from normal airway epithelium results in large part from its inaccessibility. Sputum has been collected and analyzed $(5,6)$; but sputum also contains mucus and may be modified by cellular debris, bacteria, and saliva, especially in subjects with increased respiratory secretions $(7,8)$. Airway surface fluid has been collected from dogs (9), although their use of the airway for evaporative cooling (panting) suggests the possibility that differences between canine and human airway surface fluid may exist. Sheep and human airway surface fluid have been collected in vivo and the electrolyte concentrations in the airway fluid measured $(10,11)$. However, this technique does not allow net ion transport rates and their regulation to be determined.

To better understand the physiology of the airway epithelium, we measured fluid and electrolyte transport across primary cultures of human nasal epithelia. We used cultured cells so that we could specifically study fluid transport by the surface epithelium and avoid contributions made by submucosal glands, mucus, and inflammatory cells. This approach also al-

1. Abbreviations used in this paper: $\mathrm{CF}$, cystic fibrosis; IBMX, 3-isobutyl 1-methylxanthine. 
lowed us to avoid secondary neurogenic influences on the epithelium. Because we expected the rate of transport to be small and because we wished to learn how fluid composition was changed by epithelia, we measured changes that occurred over a period of $24 \mathrm{~h}$. This approach also allowed us to ask how several mediators alter fluid transport and composition. We investigated the effects of cAMP-mediated agonists because a number of hormones, autocoids, and neurotransmitters increase cellular levels of cAMP and stimulate $\mathrm{Cl}^{-}$secretion across airway epithelia (for review see reference 1). Moreover, cAMP-mediated $\mathrm{Cl}^{-}$secretion is defective in CF airway epithelia (for review see reference 4). We also investigated the effects of amiloride, because amiloride-sensitive $\mathrm{Na}^{+}$channels at the apical surface mediate $\mathrm{Na}^{+}$absorption (measured as short-circuit current, $\left.I_{\mathrm{sc}}\right)$. In addition, amiloride-sensitive $\mathrm{Na}^{+}$absorption is increased in CF airways (12), and has been the target of pharmacological intervention for the treatment of $C F(13,14)$.

\section{Methods}

Cell culture. Nasal polyps were obtained, after polypectomy, from 16 patients with allergic rhinitis. In addition, nasal turbinate specimens were obtained, after reconstructive surgery, from two patients. Airway epithelial cells were isolated by enzyme digestion as previously described (15-17). Freshly isolated cells were seeded at a density of 5 $\times 10^{5}$ cells $/ \mathrm{cm}^{2}$ onto collagen-coated semipermeable membranes (24mm diameter Transwell; Costar Corp., Cambridge, MA) and maintained at $37^{\circ} \mathrm{C}$ in an humidified atmosphere of $5 \% \mathrm{CO}_{2}$ in air. The culture media, a mixture of 50\% DME and 50\% Ham's F12 (DME/ F12), was supplemented with $10 \mu \mathrm{g} / \mathrm{ml}$ insulin, $5 \%$ fetal calf serum (Sigma Chemical Co., St. Louis, MO), $10 \mathrm{mM}$ nonessential amino acids (Irvine Scientific, Santa Ana, CA ), $100 \mathrm{U} / \mathrm{ml}$ penicillin, and 100 $\mu \mathrm{g} / \mathrm{ml}$ streptomycin.

Fluid transport. To assess the confluency of the monolayers, transepithelial resistance was measured with an ohmmeter (EVOM; World Precision Instruments, Sarasota, FL); we used monolayers with an electrical resistance $\geq 200 \Omega$ above the resistance measured across unseeded Transwell $\left(4.5 \mathrm{~cm}^{2}\right)$ membranes. To measure net fluid transport, we used techniques similar to those described by Mangoo-Karim et al. (18). The submucosal solution was replaced with $2.5 \mathrm{ml}$ of fresh media (supplemented as described above); the mucosal solution was replaced with $100 \mu$ l of unsupplemented media. It was necessary to begin the experiment with some fluid on the mucosal surface because preliminary studies showed that if we began with no fluid on the mucosal surface, under most conditions, we could not recover sufficient fluid for analysis. Monolayers were exposed to one of the following conditions: control, no inhibitors or secretagogues; amiloride $(30 \mu \mathrm{M})$ added to the mucosal solution; cAMP agonists, $10 \mu \mathrm{M}$ forskolin and $100 \mu \mathrm{M}$ 3-isobutyl 1-methylxanthine (IBMX) added to the submucosal solution; or amiloride plus cAMP agonists, final concentrations as indicated above. To minimize evaporative losses, the mucosal solution was covered with $1.5 \mathrm{ml}$ of filter-sterilized mineral oil (previously warmed to $37^{\circ} \mathrm{C}$, humidified, and equilibrated with $5 \% \mathrm{CO}_{2}$ ). Coating the mucosal solution with mineral oil did not alter the transport properties of epithelia. Monolayers covered with oil for $24 \mathrm{~h}$ were mounted in Ussing chambers: baseline $I_{\mathrm{sc}}$ remained amiloride-sensitive and cAMPmediated secretagogues stimulated an increase in $I_{\mathrm{sc}}$ (not shown). The values were not different from monolayers not covered with oil.

After an incubation period of $24 \mathrm{~h}$, the mucosal and submucosal solutions were collected for analysis. Mucosal solutions were collected in capillary tubes to measure the recovered volume using the length of the aqueous fluid column and the known internal diameter of the capillary tubes (custom glass tubing; Drummond Scientific Co., Broomall, PA).

Ion concentrations. $\mathrm{Na}^{+}$and $\mathrm{K}^{+}$concentrations were measured with a flame photometer (Instrumentation Laboratory, Inc., Boston,
MA); $\mathrm{Cl}^{-}$concentrations were measured with a chloridometer (Laboratory Glass and Instruments Corp., New York). Neither $\mathrm{Na}^{+}$nor $\mathrm{Cl}^{-}$ concentrations were significantly modified by the addition of amiloride, forskolin and IBMX, or by supplementing the media with serum. However, $\mathrm{K}^{+}$concentrations in serum-supplemented media $(4.46 \pm 0.01 \mathrm{mM})$ were significantly greater than in unsupplemented media (4.04 $\pm 0.02 \mathrm{mM} ; n=20)$.

After equilibration with $5 \% \mathrm{CO}_{2}, \mathrm{pH}$ was measured with a micro pH electrode (model PHR-146; Lazar Research Labs, Los Angeles, CA). A standard $\mathrm{pH}$ curve was routinely obtained before measuring the $\mathrm{pH}$ of recovered solutions; standard solutions were simple electrolyte solutions to which a known quantity of $\mathrm{NaHCO}_{3}$ had been added, and then equilibrated with $5 \% \mathrm{CO}_{2}$. Over the $\mathrm{pH}$ range from 6.5 to 8.0, measurements were within $0.04 \mathrm{U}$ of the predicted $\mathrm{pH}$ values (Henderson-Hasselbalch); in addition, values were identical whether $\mathrm{pH}$ was measured using micro or bulk volumes. $\mathrm{HCO}_{3}^{-}$concentrations were calculated from the measured $\mathrm{pH}$ values using the Henderson-Hasselbalch equation.

To quantitate net $\mathrm{H}^{+}$transport, equivalent proton fluxes were determined by measuring the molar proton equivalents required to change the $\mathrm{pH}$ of the starting solution to the $\mathrm{pH}$ value of the recovered solution. While continuously gassed with a $5 \% \mathrm{CO}_{2} / 95 \% \mathrm{O}_{2}$ mixture, $15 \mathrm{ml}$ of media was titrated with $0.1 \mathrm{~N} \mathrm{HCl}$ to the appropriate $\mathrm{pH}$ values. Proton fluxes were determined separately for serum-supplemented (submucosal) and unsupplemented (mucosal) media ( $n=3-$ 6 ); equivalent proton fluxes were adjusted for the volume of recovered fluid.

For each monolayer, the concentration of unmeasured anions (anion gap) was calculated as the sum of $\mathrm{Na}^{+}$and $\mathrm{K}^{+}$concentrations minus the $\mathrm{Cl}^{-}$and $\mathrm{HCO}_{3}^{-}$concentrations. On the basis of the manufacturer's insert, the concentrations of 21 amino acids, pyruvate, biphosphate, sulfate, nitrate, and trace additives accounted for over $90 \%$ of the anion gap of freshly prepared, unsupplemented media ( $16 \mathrm{mM})$; the media also contained $17.5 \mathrm{mM}$ D-glucose.

Lactate concentrations were measured using an enzyme assay (735UV; Sigma Chemical Co.). Lactate concentrations in unsupplemented and serum-supplemented media were $0.1 \pm 0.1$ and $1.1 \pm 0.1 \mathrm{mM}$, respectively.

Data analysis. For each tissue specimen, one to six monolayers were used for each condition (control, amiloride, cAMP agonists, and amiloride plus cAMP agonists). When more than one monolayer was studied per condition, a single value (mean of two to six monolayers) was obtained for each condition. Thus each specimen contributed equally to the final means. All studies from an individual tissue specimen were carried out concurrently. Data are presented as mean \pm SEM. Statistically significant differences between means were assessed using one- and two-way analysis of variance; $P$ values $\leq 0.05$ were considered statistically significant.

Reagents. Amiloride was a gift from Merck Sharp \& Dohme (West Point, PA); SCH 28080 was obtained from Schering Corporation (Kenilworth, NJ). All other chemicals were purchased from Sigma Chemical Co.

\section{Results}

Fluid absorption and secretion. We first determined the volume of fluid that could be recovered from cultured epithelia. We replaced the mucosal solution of epithelial monolayers with $100 \mu \mathrm{l}$ of media, and then coated it with mineral oil. 5-10 min later, $95.4 \pm 0.9 \mu$ l of the solution was recovered $(n=20)$; this value served as the predicted volume that should be recovered from monolayers that did not absorb or secrete fluid.

Fig. $1 A$ shows the volume of mucosal fluid recovered from airway epithelia after the 24-h incubation period. The volume recovered from control monolayers was less than the $95 \mu \mathrm{l}$ predicted for no net fluid transport. However, the volume recovered from amiloride-exposed monolayers was not different 


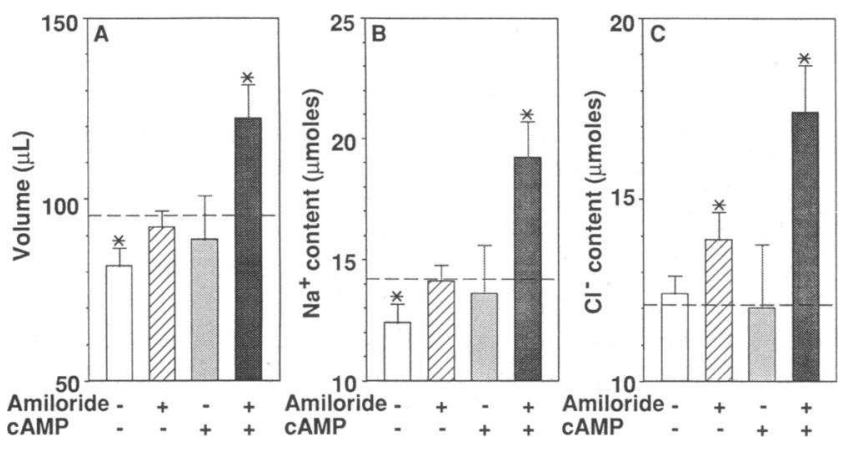

Figure 1. Effect of amiloride and cAMP on $(A)$ volume, $(B) \mathrm{Na}^{+}$ content, and $(C) \mathrm{Cl}^{-}$content of the mucosal solution recovered from cultured airway epithelia. The plus sign at the bottom of the figure indicates the presence of amiloride $(30 \mu \mathrm{M})$ in the mucosal solution or cAMP agonists in the submucosal solution; cAMP represents the presence of forskolin $(10 \mu \mathrm{M})$ and IBMX $(100 \mu \mathrm{M})$ in the submucosal solution. The dashed line indicates the predicted volume or ion content recoverable from the mucosal surface (see Results for details); the predicted volume and $\mathrm{Na}^{+}$and $\mathrm{Cl}^{-}$contents were 95.4 \pm 0.9 $\mu \mathrm{l}, 14.2 \pm 0.2 \mu \mathrm{mol}$, and $12.1 \pm 0.1 \mu \mathrm{mol}$, respectively. Values are mean \pm SEM, $n=12$; Values that differ significantly from predicted values.

from the predicted value. This result indicates that, under basal conditions, airway epithelia absorb fluid. Because previous work $(19,20)$ has shown the presence of amiloride-sensitive, electrogenic $\mathrm{Na}^{+}$absorption by canine and human airway epithelia, these results suggest that active $\mathrm{Na}^{+}$absorption is responsible for the fluid absorption.

In contrast, addition of both amiloride and cAMP agonists (forskolin and IBMX) stimulated active fluid secretion (Fig. 1 $A$ ). This result is consistent with previous studies that have shown cAMP-mediated secretagogues stimulate $\mathrm{Cl}^{-}$secretion across airway epithelia (21-24).

One surprising result was the apparent lack of fluid secretion in response to the addition of cAMP agonists alone (Fig. 1 $A)$. However, examination of the results obtained from individual monolayers showed significant intersubject variability. Fig. $2 B$ shows that the response to cAMP was heterogeneous: cAMP agonists stimulated fluid secretion in some monolayers, whereas in others they stimulated fluid absorption. This variability is not explained by experimental error because multiple monolayers obtained from a single specimen always showed a consistent pattern of response. Furthermore, the response to amiloride or amiloride plus cAMP agonists was much more homogeneous: both treatment groups had a nearly uniform increase in mucosal fluid volume (Fig. 2, $A$ and $C$ ).

Transepithelial transport of $\mathrm{Na}^{+}$and $\mathrm{Cl}^{-}$. To gain insight into the mechanisms responsible for the fluid transport, we measured the $\mathrm{Na}^{+}$content of the mucosal fluid $\left(\mathrm{Na}^{+}\right.$concentration $\times$ recovered volume $)$. We compared this value with the $\mathrm{Na}^{+}$content that would be recovered from the mucosal surface if there was no net fluid transport $\left(\mathrm{Na}^{+}\right.$concentration of the initial mucosal media $\times$ the predicted recoverable volume, $95.4 \mu \mathrm{l}$ ). The pattern of changes for each condition are the same as observed for the changes in fluid volume (compare Fig. 1, $A$ and $B$ ). That is, for control monolayers, the content of $\mathrm{Na}^{+}$on the mucosal surface decreased; amiloride prevented the decrease. The combination of amiloride plus cAMP agonists increased the mucosal $\mathrm{Na}^{+}$content. These results suggest

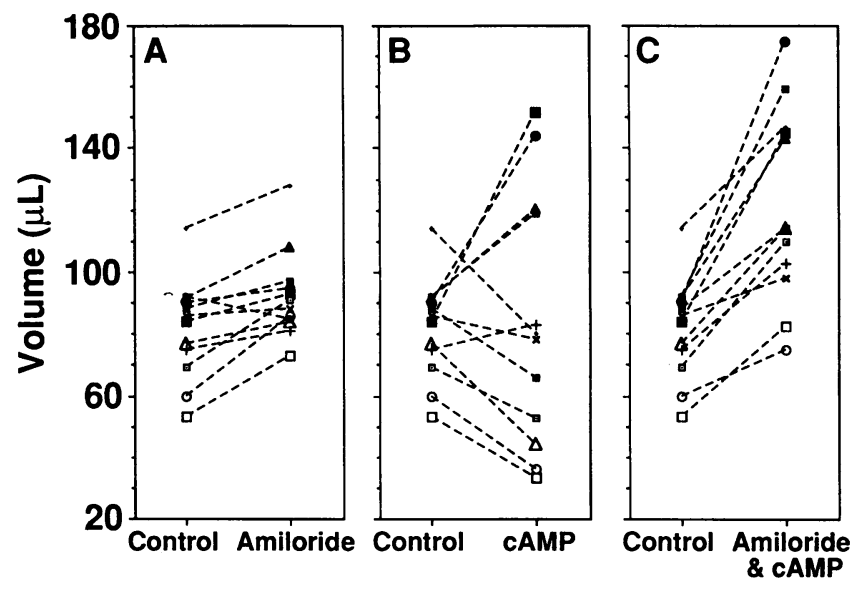

Figure 2. Effect of $(A)$ amiloride, $(B)$ cAMP agonists, and $(C)$ amiloride plus CAMP agonists on the volume of recovered mucosal fluid. Each point represents data from a different specimen (the mean value of one to six monolayers). Dashed lines connect data points from the same specimen. Other details are as in Fig. 1.

that the distribution of fluid across airway epithelia parallels the distribution of $\mathrm{Na}^{+}$.

Interestingly, $\mathrm{Cl}^{-}$transport differed in two ways from that of fluid and $\mathrm{Na}^{+}$transport. First, mucosal $\mathrm{Cl}^{-}$recovered from control monolayers was near the predicted value (Fig. $1 \mathrm{C}$ ). This observation suggests that under basal conditions $\mathrm{Na}^{+} \mathrm{ab}^{-}$ sorption may be accompanied by anions other than $\mathrm{Cl}^{-}$(discussed below). Second, mucosal $\mathrm{Cl}^{-}$recovered from amiloride-treated monolayers was greater than predicted. One explanation for this result is that there is $\mathrm{Cl}^{-}$conductance in the apical membrane under basal conditions and that addition of amiloride hyperpolarizes the apical membrane, thereby increasing the electrochemical gradient for $\mathrm{Cl}^{-}$efflux. This possibility is consistent with the observations of Boucher and colleagues $(12,20)$. This explanation would still, however, require absorption of some other anion. The content of $\mathrm{Cl}^{-}$on the mucosal surface was greatest for monolayers exposed to both amiloride and cAMP agonists: cAMP agonists would be expected to further increase apical $\mathrm{Cl}^{-}$conductance.

Transepithelial $\mathrm{Na}^{+}$and $\mathrm{Cl}^{-}$concentration gradients. Fig. 3, $A$ and $B$, shows the concentrations of $\mathrm{Na}^{+}$and $\mathrm{Cl}^{-}$in the mucosal and submucosal solutions. The concentrations of $\mathrm{Na}^{+}$ in the mucosal and submucosal solutions were not significantly different under basal conditions or in the presence of either amiloride or cAMP agonists added alone (Fig. $3 A$ ). However, the mucosal $\mathrm{Cl}^{-}$concentration exceeded the submucosal $\mathrm{Cl}^{-}$ concentration under basal conditions (Fig. $3 \mathrm{~B}$ ). The $\mathrm{Cl}^{-}$concentration gradient under control conditions could be accounted for by net $\mathrm{Na}^{+}$and fluid absorption in the absence of net transepithelial $\mathrm{Cl}^{-}$transport (Fig. 1, $A-C$ ); some anion other than $\mathrm{Cl}^{-}$accompanied $\mathrm{Na}^{+}$absorption. The mucosal $\mathrm{Cl}^{-}$ concentration also exceeded the submucosal concentration in the presence of amiloride (Fig. $3 \mathrm{~B}$ ). As previously noted, this result is consistent with a basal degree of apical $\mathrm{Cl}^{-}$conductance. A surprising finding, and one that is difficult to explain, is that cAMP agonists abolished the transepithelial $\mathrm{Cl}^{-}$concentration gradient. This result may have been due to an insufficient driving force for $\mathrm{Cl}^{-}$efflux through an apical $\mathrm{Cl}^{-}$conductance under this condition. Alternatively, cAMP may have inhibited some $\mathrm{Cl}^{-}$/anion exchange process. 

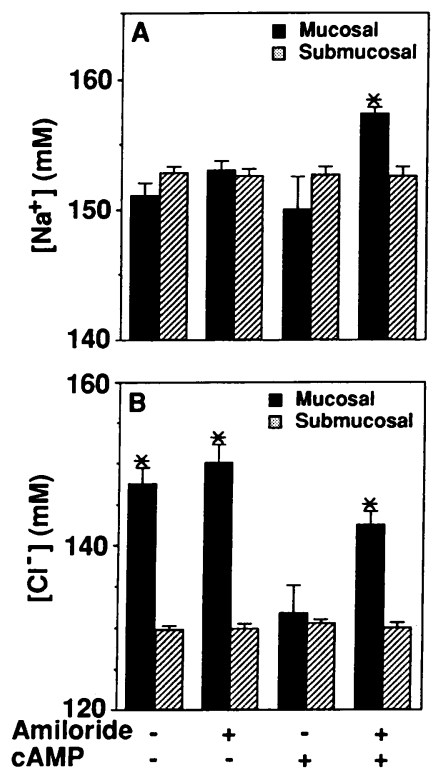

Figure 3. Effect of amiloride and CAMP agonists on the concentration of $(A) \mathrm{Na}^{+}$and (B) $\mathrm{Cl}^{-}$in recovered mucosal and submucosal solutions. Mucosal and submucosal $\mathrm{Na}^{+}$ concentrations at the beginning of the experiment were $148.8 \pm 0.6$ and $149.8 \pm 0.5 \mathrm{mM}$, respectively; initial mucosal and submucosal $\mathrm{Cl}^{-}$concentrations were $126.7 \pm 0.7$ and $126.8 \pm 0.6 \mathrm{mM}$, respectively. *Mucosal concentrations that differ significantly from submucosal concentrations. Other details are as in Fig. 1.

When monolayers were exposed to the combination of amiloride plus cAMP agonists, the concentration of both $\mathrm{Na}^{+}$ and $\mathrm{Cl}^{-}$in the mucosal solution exceeded the concentration in the submucosal solution. This result is consistent with secretion of $\mathrm{NaCl}$-rich fluid and passive water transport from submucosal to mucosal surface in response to an osmotic pressure difference.

Absorption of $\mathrm{K}^{+}$and secretion of $\mathrm{H}^{+}$. Although $\mathrm{K}^{+}$and $\mathrm{H}^{+}$concentrations are much lower than $\mathrm{Na}^{+}$and $\mathrm{Cl}^{-}$concentrations, the transport of $\mathrm{K}^{+}$and $\mathrm{H}^{+}$across airway epithelia could alter the composition of the respiratory tract fluid. Under control conditions, the mucosal $\mathrm{K}^{+}$content decreased (Fig. 4 $A$ ); this result indicates that airway epithelia absorb $\mathrm{K}^{+}$under basal conditions. Mucosal amiloride had no effect on $\mathrm{K}^{+} \mathrm{ab}-$ sorption. However, cAMP agonists inhibited net $\mathrm{K}^{+}$absorption.

The decrease in $\mathrm{K}^{+}$content in the apical compartment is the result of active transport. It cannot be explained by passive movement through paracellular pathways because the lumen-

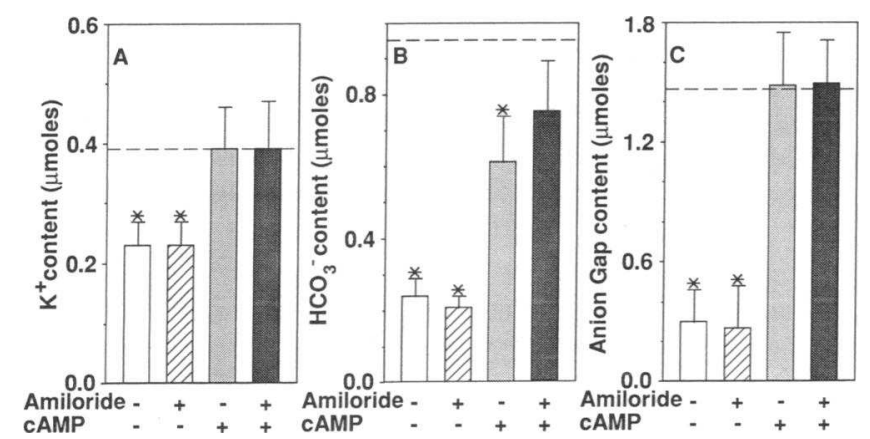

Figure 4. Effect of amiloride and cAMP agonists on the content of $(A)$ $\mathrm{K}^{+},(B) \mathrm{HCO}_{3}^{-}$, and $(C)$ anion gap in mucosal solution recovered from cultured airway epithelia. The dashed line indicates the predicted ion content recoverable from the mucosal surface (see Results for details); the predicted content for $\mathrm{K}^{+}, \mathrm{HCO}_{3}^{-}$and anion gap were: $0.39 \pm 0.01,0.97 \pm 0.05$, and $1.5 \pm 0.1 \mu \mathrm{mol}$, respectively. Other details are as in Fig. 1.

negative transepithelial voltage and the transepithelial $\mathrm{K}^{+}$concentration difference at the start of the study (mucosal $\mathrm{K}^{+}$concentration $4.04 \mathrm{mM}$ and submucosal $\mathrm{K}^{+}$concentration 4.46 $\mathrm{mM}$, see Methods) would favor $\mathrm{K}^{+}$secretion rather than absorption. In addition, the predicted electrochemical gradient for $\mathrm{K}^{+}$across the apical membrane should favor $\mathrm{K}^{+}$efflux from the cell rather than $\mathrm{K}^{+}$influx (1). Thus an energy-dependent transport process appears to be responsible for absorption of $\mathrm{K}^{+}$by the epithelial cells.

The changes in $\mathrm{K}^{+}$content were paralleled by changes in the $\mathrm{HCO}_{3}^{-}$content (Fig. $4 \mathrm{~B}$ ) and pH (Table I). The decrease in $\mathrm{pH}$ indicates net $\mathrm{H}^{+}$secretion or, the equivalent, $\mathrm{HCO}_{3}^{-}$ absorption. We measured equivalent proton flux to quantitate net $\mathrm{H}^{+}$secretion. Net proton flux into the mucosal solution under basal conditions ( Table I) was greater in magnitude than the decrease in $\mathrm{HCO}_{3}^{-}$content (Fig. $4 \mathrm{~B}$ ). This observation is consistent with the buffering effects of media and $\mathrm{CO}_{2}$. cAMP agonists inhibited net $\mathrm{H}^{+}$secretion (Table $\mathrm{I}$ ) and the decrease in $\mathrm{HCO}_{3}^{-}$content (Fig. $4 \mathrm{~B}$ ). Amiloride had no effect, in either the presence or absence of cAMP agonists.

The presence of $\mathrm{K}^{+}$absorption and $\mathrm{H}^{+}$secretion, both of which were inhibited by cAMP agonists, suggested the possibility that $\mathrm{K}^{+}$absorption and $\mathrm{H}^{+}$secretion might be coupled. It seemed possible that an apical membrane $\mathrm{K}^{+}$pump, for example, $\mathrm{H}^{+} / \mathrm{K}^{+}$-ATPase, might contribute to both results. Note, however, that it is unlikely that $\mathrm{H}^{+} / \mathrm{K}^{+}$-ATPase would be the sole mechanism of net $\mathrm{H}^{+}$secretion because the magnitude of $\mathrm{H}^{+}$secretion (equivalent proton flux) significantly exceeded net $\mathrm{K}^{+}$absorption (Fig. $4 \mathrm{~A}$ ).

To test whether $\mathrm{K}^{+}$was absorbed via $\mathrm{H}^{+} / \mathrm{K}^{+}$-ATPase, we measured net transport across monolayers exposed to mucosal SCH 28080, a specific inhibitor of $\mathrm{H}^{+} / \mathrm{K}^{+}$-ATPase in some epithelial cells (25-28). Fig. 5 shows that $\mathrm{SCH} 28080$ inhibited net $\mathrm{K}^{+}$absorption. SCH 28080 had no effect on net fluid or $\mathrm{Na}^{+}$absorption (not shown). $\mathrm{Net}^{+}$secretion was not inhibited by SCH 28080; this observation supports the notion that $\mathrm{H}^{+}$secretion is not mediated solely by $\mathrm{SCH} 28080$-sensitive pathways (discussed below). These results are consistent with $\mathrm{K}^{+}$absorption via $\mathrm{H}^{+} / \mathrm{K}^{+}$-ATPase. Nevertheless, SCH 28080 may have effects in addition to inhibition of $\mathrm{H}^{+} / \mathrm{K}^{+}$-ATPase.

Table I. Effect of Amiloride and cAMP Agonists on $p H$ and Net $\mathrm{H}^{+}$Flux

\begin{tabular}{lcccccc}
\hline & \multicolumn{2}{c}{ Mucosal } & & \multicolumn{2}{c}{ Submucosal } \\
\cline { 2 - 3 } \cline { 5 - 6 } \multicolumn{1}{c}{ Condition } & $\mathrm{pH}$ & $\mathrm{H}^{+}$flux & & $\mathrm{pH}$ & $\mathrm{H}^{+}$flux \\
\hline & & $\mu m o l$ & & $\mu m o l$ \\
Control & $6.47 \pm 0.06^{*}$ & $0.81 \pm 0.04$ & & $6.90 \pm 0.02$ & $12 \pm 1.3$ \\
$\begin{array}{l}\text { Amiloride } \\
\text { cAMP }\end{array}$ & $6.41 \pm 0.06^{*}$ & $1.03 \pm 0.05$ & & $6.93 \pm 0.02$ & $9 \pm 1$ \\
$\begin{array}{l}\text { Amiloride and } \\
\quad \text { cAMP }\end{array}$ & $6.83 \pm 0.05$ & $0.31 \pm 0.01^{\ddagger}$ & & $6.86 \pm 0.03$ & $15 \pm 1.5$ \\
& $6.81 \pm 0.05$ & $0.55 \pm 0.02^{\ddagger}$ & & $6.88 \pm 0.02$ & $17 \pm 1.5$
\end{tabular}

$\mathrm{H}^{+}$flux represents the molar proton equivalents required to change the $\mathrm{pH}$ of the starting media to the $\mathrm{pH}$ values listed above (see Methods for details); flux determinations take into account the volume of recovered solution and whether the solution was supplemented with serum (submucosal solutions). ${ }^{*}$ Mucosal pH values that differ significanily from submucosal $\mathrm{pH}$ values; ${ }^{\ddagger}$ Mucosal proton fluxes for cAMP-treated epithelia that differ significantly from the mucosal flux determinations for epithelia not treated with cAMP agonists. 

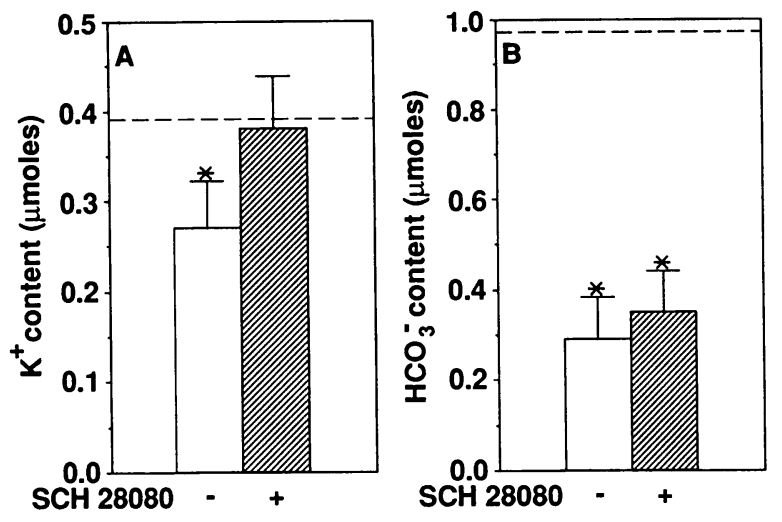

Figure 5. Effect of SCH 28080 on $(A) \mathrm{K}^{+}$and $(B) \mathrm{HCO}_{3}^{-}$content in the mucosal solution recovered from cultured airway epithelia. The plus sign at the bottom of the figure indicates the presence of SCH $28080(30 \mu \mathrm{M})$. The dashed line indicates the predicted ion content recoverable from the mucosal surface (see Results for details); the predicted values for $\mathrm{K}^{+}$and $\mathrm{HCO}_{3}^{-}$contents were $0.39 \pm 0.01$ and $0.97 \pm 0.05 \mu \mathrm{mol}$, respectively. Monolayers were not exposed to amiloride or cAMP agonists. Values are mean \pm SEM, $n=6$. Other details are as in Fig. 1.

Transepithelial $\mathrm{K}^{+}$and $\mathrm{H}^{+}$concentration gradients. Fig. 6 $A$ shows the $\mathrm{K}^{+}$concentrations in the mucosal and submucosal solutions. The mucosal and submucosal $\mathrm{K}^{+}$concentrations differed by $\leq 2 \mathrm{mM}$ and presumably had minimal effects on net fluid transport.

We considered the mechanisms regulating acid-base balance by examining the $\mathrm{pH}$ and net $\mathrm{H}^{+}$flux. Table I shows that epithelial monolayers acidified both mucosal and submucosal solutions. This result indicates that airway epithelia produced an organic acid during the $24-\mathrm{h}$ study period. In addition, under basal conditions, epithelial monolayers generated a transepithelial $\mathrm{H}^{+}$concentration gradient with the mucosal solution being more acidic than the submucosal solution. This $\mathrm{pH}$ gradient was accompanied by an increase in the anion gap of the submucosal solution (Fig. $6 C$ ). The sizable anion gap is consistent with the submucosal accumulation of an anion other than $\mathrm{Cl}^{-}$or $\mathrm{HCO}_{3}^{-}$. Taken together, the data are consistent with the net absorption of the sodium salt of an organic acid.

Lactic acid production. We considered that lactate, a byproduct of glucose catabolism, might be responsible for some of the unmeasured anions in the recovered solutions and account for acidification of the media. Moreover, lactate production by native canine airway epithelia has been reported (29). Fig. 7 shows that lactate accumulated in both mucosal and submucosal solutions. Quantitatively, lactate production was greater than the total proton flux (Table I) and the change in anion gap (Fig. 6). However, these observations are consistent with the notion that airway epithelia also consume organic anions, e.g., amino acids and pyruvate. Although the concentrations of pyruvate and amino acids were not measured, the decrease in mucosal anion gap (Fig. $6 C$ ) is also consistent with the consumption of organic anions. Lactate production was not due to coating the mucosal solution with mineral oil because lactate concentrations in media collected from epithelial monolayers coated with mineral oil (Fig. 7) were similar in magnitude to the lactate concentrations in media collected from uncoated airway monolayers $(13 \pm 3.1 \mathrm{mM} ; n=4)$.
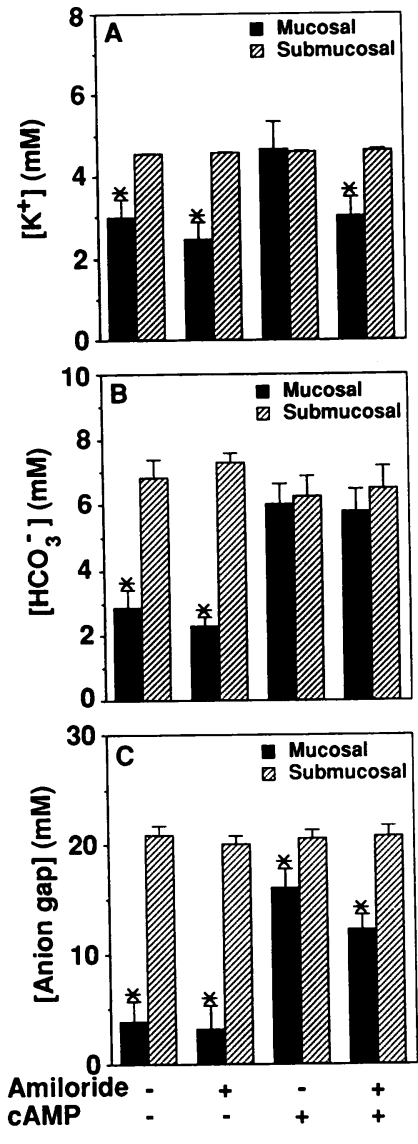

Figure 6. Effect of amiloride and cAMP agonists on the concentration of $(A) \mathrm{K}^{+},(B)$ $\mathrm{HCO}_{3}^{-}$, and $(C)$ anion gap in the mucosal and submucosal solutions. Initial mucosal and submucosal $\mathrm{K}^{+}$concentrations were $4.04 \pm 0.02$ and $4.46 \pm 0.01$ $\mathrm{mM}$, respectively ( see Methods); initial mucosal and submucosal $\mathrm{HCO}_{3}^{-}$concentrations were $10.2 \pm 0.4$ and $10.5 \pm 0.6$ $\mathrm{mM}$, respectively. Initial mucosal and submucosal anion gap concentrations were $15.8 \pm 0.7$ and $16.9 \pm 0.9 \mathrm{mM}$, respectively. Values are mean $\pm \mathrm{SEM}, n=12$. Other details are as in Fig. 3.

\section{Discussion}

Understanding the fluid and electrolyte transport properties of airway epithelia requires knowledge of the rate of fluid transport, its regulation, and the ion composition of the surface fluid. This study provides the first such measurements in cultured human airway epithelia. Some of the results would be predicted by previous measurements of transepithelial ion fluxes; some were unexpected.

Fluid absorption by airway epithelium under basal conditions was consistent with predictions of previous studies (12, $30-32$ ) that showed an absorptive radiotracer $\mathrm{Na}^{+}$flux and an amiloride-sensitive $I_{\mathrm{sc}}$. Our results and these previous studies indicate that active $\mathrm{Na}^{+}$absorption drives fluid absorption. Because the rate of $\mathrm{Na}^{+}$absorption by airway epithelia from patients with CF may be increased $(12,20)$, our results support the possibility that amiloride (or analogues thereof) may be of

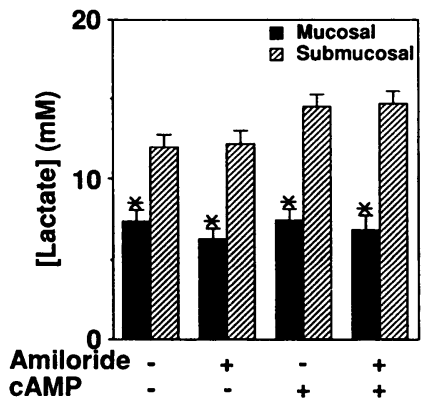

Figure 7. Effect of amiloride and CAMP agonists on lactate concentrations in recovered mucosal and submucosal solutions. Initial mucosal and submucosal lactate concentrations were $0.1 \pm 0.1$ and $1.1 \pm 0.1$ $\mathrm{mM}$, respectively. Values are mean \pm SEM, $n=12$. Other details are as in Fig. 3. 
benefit in reducing fluid absorption across $\mathrm{CF}$ airway epithelia $(13,14)$, if a sufficient concentration of amiloride can be maintained at the airway luminal surface.

We found the $\mathrm{Cl}^{-}$flux and concentration gradients surprising. Under basal conditions there was net $\mathrm{Na}^{+}$and fluid absorption, but there was no net transepithelial $\mathrm{Cl}^{-}$transport (Fig. $1 C$ ). This result suggests that some anion other than $\mathrm{Cl}^{-}$ accompanies $\mathrm{Na}^{+}$absorption. This interpretation is consistent with isotope flux measurements that indicate that net $\mathrm{Na}^{+} \mathrm{ab}-$ sorption $\left(1.2 \pm 0.3 \mu \mathrm{eq} / \mathrm{cm}^{2}\right.$ per $\mathrm{h}$ ) across open-circuited human bronchial epithelium is not matched by $\mathrm{Cl}^{-}$absorption $\left(0.5 \pm 0.3 \mu \mathrm{eq} / \mathrm{cm}^{2}\right.$ per $\left.\mathrm{h}\right)(33)$. Mechanistically, it is possible that $\mathrm{Cl}^{-}$accompanies $\mathrm{Na}^{+}$absorption but that $\mathrm{Cl}^{-}$absorption would then have to be counterbalanced by $\mathrm{Cl}^{-}$secretion via a process that results in the net exchange of submucosal $\mathrm{Cl}^{-}$for some other mucosal anion.

For monolayers treated with the combination of amiloride plus cAMP agonists, the epithelia secreted a $\mathrm{NaCl}$-rich fluid. This result is consistent with previous reports $(21,31,32)$ of transepithelial isotope fluxes and $I_{\mathrm{sc}}$ that indicate that cAMP stimulates $\mathrm{Cl}^{-}$secretion by airway epithelia.

When added alone, cAMP agonists had no statistically significant effect on net transport. There was, however, significant intersubject variability (Figs. 1 and 2): cAMP stimulated net fluid secretion in some monolayers, whereas in others cAMP stimulated net fluid absorption. Our results do not identify the factor(s) that determine(s) whether an epithelium from one subject will absorb or secrete fluid when stimulated by cAMP. There are several previous observations that are relevant to this problem. First, cAMP agonists might directly stimulate $\mathrm{Na}^{+}$ absorption; a cAMP-mediated increase in $\mathrm{Na}^{+}$absorption has been observed for canine tracheal epithelium bathed in $\mathrm{Cl}^{-}$free media (34) and for CF epithelia (12). In addition, there is strong evidence for cAMP-induced $\mathrm{Na}^{+}$absorption across alveolar epithelia $(35,36,37)$ as well as epithelia of rat cortical collecting duct (38), amphibian distal nephron (A6) (39), turtle urinary bladder (40), and frog skin (41). Second, cAMP would be expected to increase apical $\mathrm{Cl}^{-}$conductance $(20,42)$. However, the rate and direction of $\mathrm{Cl}^{-}$movement will be determined by the electrical potential difference across the apical membrane. The apical voltage will in turn be regulated in large part by the apical $\mathrm{Na}^{+}$conductance $(43,44)$. Thus, we speculate that the magnitude of apical $\mathrm{Na}^{+}$conductance may play a part in modulating the effect of cAMP on fluid transport. This suggestion is consistent with our finding that, in the presence of amiloride, cAMP agonists stimulated secretion; by hyperpolarizing the apical membrane, amiloride would increase the driving force for $\mathrm{Cl}^{-}$efflux.

Another unexpected finding was the absorption of $\mathrm{K}^{+}$by airway epithelia. This may have been unrecognized in previous studies because the magnitude of $\mathrm{K}^{+}$flux is much less than $\mathrm{Na}^{+}$and $\mathrm{Cl}^{-}$fluxes. Moreover, $\mathrm{K}^{+}$absorption may be electrically neutral and thus undetectable in measurements of $I_{\mathrm{sc}}$. Inhibition by SCH 28080 (Fig. 5) suggests that $\mathrm{K}^{+}$absorption occurs via an apical membrane $\mathrm{H}^{+} / \mathrm{K}^{+}$-ATPase.

A transepithelial $\mathrm{pH}$ gradient was generated with a more acidic mucosal solution (Table I and Fig. 6). Interestingly, cAMP agonists inhibited both $\mathrm{K}^{+}$absorption and the generation of the $\mathrm{pH}$ gradient. This inhibitory effect of cAMP agonists is consistent with the notion that $\mathrm{K}^{+}$absorption and $\mathrm{H}^{+}$secretion may be coupled, for example, via $\mathrm{H}^{+} / \mathrm{K}^{+}$-ATPase. However, differences in the magnitude of $\mathrm{H}^{+}$and $\mathrm{K}^{+}$flux (Fig. $4 \mathrm{~A}$ and Table I) suggest an additional mechanism for net $\mathrm{H}^{+}$secretion, which is inhibited by cAMP agonists. We recently reported that cAMP stimulates an increase in apical $\mathrm{HCO}_{3}^{-}$conductance in airway epithelia (45). Our results are consistent with the notion that the inhibitory effect of cAMP agonists on $\mathrm{H}^{+}$secretion may be due to a cAMP-induced increase in apical $\mathrm{HCO}_{3}^{-}$conductance.

Cultured airway epithelia acidified the media; acidification was due in part to lactic acid production (Fig. 7). Because lactate concentrations were not equal in the mucosal and submucosal solutions, we considered physical factors that might account for the transepithelial lactate concentration gradients: a Donnan effect, the $\mathrm{pH}$ gradient, and the transepithelial voltage difference.

By attracting or repelling ions, charges on impermeable proteins may establish an ion gradient (Donnan effect). Using dialysis tubing that allows passage of molecules $<3,500 \mathrm{D}$, we observed lactate accumulation in media without serum $(5.08 \pm 0.02 \mathrm{mM})$ rather than serum-supplemented media $(4.90 \pm 0.04 \mathrm{mM} ; n=3)$. Thus, the observed transepithelial lactate concentration gradients were not due to the presence of serum in the submucosal solution.

Using the Henderson-Hasselbalch equation, the $\mathrm{pK}_{\mathrm{a}}$ for lactic acid (3.87) indicates that the concentration of lactic acid is much lower than lactate at $\mathrm{pH} 7$ (46). In the presence of a transepithelial $\mathrm{pH}$ gradient, the ratio of lactate to lactic acid will differ for the mucosal and submucosal solutions. If the nonionic species (lactic acid) is membrane permeable and its concentration reaches an equilibrium across airway monolayers, then the measured transepithelial $\mathrm{pH}$ gradient under control conditions (submucosal $\mathrm{pH} 6.9 \pm 0.02$ vs. mucosal $\mathrm{pH}$ $6.47 \pm 0.06$ ) could account for a ratio of submucosal to mucosal lactate concentration of 2.7. This predicted ratio of lactate concentrations exceeds the measured ratio (1.6) of submucosal to mucosal lactate concentrations (Fig. 7). Therefore, the transepithelial $\mathrm{pH}$ gradients observed under control and amiloridetreated conditions could account for the lactate concentration gradients. However, transepithelial $\mathrm{pH}$ gradients were not present in cAMP-treated epithelia, thus another mechanism must account for the lactate concentration gradients in epithelia treated with cAMP agonists.

Using the Nernst equation, a lumen-negative transepithelial voltage of $-12.7 \mathrm{mV}$ could account solely for the observed transepithelial lactate concentration gradient (1.6) under basal conditions; a voltage of $-19.7 \mathrm{mV}$ could account solely for the concentration gradient (2.2) observed for epithelia treated with amiloride plus cAMP agonists. Although we did not measure the transepithelial voltages of these monolayers, values within this range have been reported for airway epithelia $(1,12,20)$. Furthermore, although amiloride decreases and cAMP increases transepithelial voltage acutely $(1,12,20)$, their effects on voltage after a period of $24 \mathrm{~h}$ are unknown. Thus, the combination of $\mathrm{pH}$ gradient and transepithelial voltage may account for the observed transepithelial lactate concentration gradients.

It is interesting to compare the electrolyte concentrations we report for mucosal fluid from cultured human airway epithelia, with previously reported values for airway surface fluid collected via a variety of techniques. Table II shows substantial variability in $\mathrm{Na}^{+}$and $\mathrm{Cl}^{-}$concentrations in different species and airway regions as well as the presence of transepithelial concentration gradients. It is difficult to discern a specific pattern, but it is interesting that the $\mathrm{Na}^{+}$and $\mathrm{Cl}^{-}$concentrations 
Table II. Comparison of the Ion Concentrations in the Recovered Mucosal Solution under Basal Conditions with Previously Reported Concentrations in Airway Surface Fluid

\begin{tabular}{|c|c|c|c|c|c|}
\hline Source & $\mathrm{Na}^{+}$ & $\mathrm{Cl}^{-}$ & $\mathrm{K}^{+}$ & $\mathrm{HCO}_{3}^{-}$ & Reference \\
\hline \multicolumn{6}{|c|}{ Cultured human airway epithelia } \\
\hline mucosal solution & $151 \pm 0.9$ & $148 \pm 2$ & $3.0 \pm 0.4$ & $2.8 \pm 0.6$ & - \\
\hline \multicolumn{6}{|l|}{ Human trachea in vivo } \\
\hline Nonsurgical case & $93 \pm 4$ & $91 \pm 5$ & $11 \pm 1$ & - & 11 \\
\hline Surgical case & $91 \pm 12$ & $108 \pm 15$ & $19 \pm 3$ & low & \\
\hline \multicolumn{6}{|l|}{ Canine airway in vivo } \\
\hline Trachea & $145 \pm 14$ & $142 \pm 13.7$ & $27 \pm 3.1$ & $32 \pm 5.9$ & 9 \\
\hline Bronchus & $121 \pm 13$ & $106 \pm 4.7$ & $37 \pm 4.5$ & $52 \pm 10$ & \\
\hline Plasma & $142 \pm 3$ & $112 \pm 2.4$ & $5.2 \pm 0.2$ & $26 \pm 0.9$ & \\
\hline \multicolumn{6}{|l|}{ Ferret airway in vitro } \\
\hline Trachea & $167 \pm 1.7$ & $121 \pm 5.1$ & $9.0 \pm 0.05$ & $13^{*}$ & 54 \\
\hline Ringer's Solution & 145 & 126 & 5.9 & 26 & \\
\hline \multicolumn{6}{|l|}{ Sheep lung } \\
\hline Fetal lung liquid & $150 \pm 1.3$ & $157 \pm 4.1$ & $6.3 \pm 0.7$ & $2.8 \pm 0.3$ & 50 \\
\hline Plasma & $150 \pm 0.7$ & $107 \pm 1.3$ & $4.8 \pm 0.2$ & $24 \pm 1.2$ & \\
\hline
\end{tabular}

* Value calculated from the measured $\mathrm{pH}$ using the Henderson-Hasselbalch equation.

we measured are higher than the hypoosmotic fluid recovered from human trachea (see Table II). A similarity between our results and most of the previous reports is the reduced mucosal $\mathrm{HCO}_{3}^{-}$concentration. These results are consistent with net $\mathrm{H}^{+}$ secretion across airway epithelia. However, one consistent difference between our results and previous reports is the $\mathrm{K}^{+}$concentrations: although $\mathrm{K}^{+}$concentrations varied considerably in previous reports $(6-37 \mathrm{mM})$, we found a lower concentration $(3 \mathrm{mM})$. It is possible that the results of previous studies reflect the contributions of mucus, submucosal gland secretion, and intracellular ions ( from injured epithelial cells or cells resident in the airway lumen ). Alternatively, there may be substantial differences in the mechanisms of transepithelial $\mathrm{K}^{+}$ transport in different species or different regions of the airway. Finally, it is possible that cultured airway cells may not express a property of native epithelia (e.g., $\mathrm{K}^{+}$secretion), although other properties appear to be retained in primary culture.

The $\mathrm{pH}$ of the recovered mucosal fluid ranged from 6.4 to 6.8. These values are within the range measured in vivo (47, 48 ) and the results are consistent with $\mathrm{H}^{+}$secretion by airway epithelia. In fact, in vitro, ferret airway epithelia maintained airway surface fluid at an acidic $\mathrm{pH}(6.85 \pm 0.03)$ even when the submucosal solution was significantly alkalinized (49). Our observation of net $\mathrm{H}^{+}$secretion and low $\mathrm{HCO}_{3}^{-}$concentration is also consistent with the low $\mathrm{pH}$ of rabbit alveolar fluid $(6.92 \pm 0.04)(50)$ and the low $\mathrm{HCO}_{3}^{-}$concentration in fetal sheep lung liquid ( 51 ).

It is of interest to consider how the volume of fluid transported by cultured airway epithelia may affect the airways. The aqueous layer of airway surface fluid is estimated to be $\sim 5 \mu \mathrm{m}$ in depth in vivo (3); this corresponds to a volume of $500 \mathrm{nl}$ of fluid over each $\mathrm{cm}^{2}$ of epithelium. Thus, our measurements of net fluid transport under basal conditions correspond to the absorption of six times this volume of fluid over a period of 24 h. In contrast, for epithelia treated with amiloride and cAMP agonists, net fluid transport corresponds to the secretion of 12 times this volume over $24 \mathrm{~h}$. This rate of fluid transport is less than that measured across native canine tracheal (52) and human nasal epithelia (53); this difference may be due to culture conditions. Nevertheless, the rate of fluid transport by airway epithelia is within a range that is likely to impact on airway physiology. Furthermore, these results suggest that the inability to modify the rate of ion, and thus fluid transport across the airway, as occurs in CF epithelia, may significantly alter airway physiology.

In summary, these results provide new insights into the transport function of airway epithelia. An advantage of our techniques is that they isolate the transport properties to the surface airway epithelium; it will, however, also be interesting to learn what contribution submucosal gland secretions make to the composition of the respiratory tract fluid. In addition, it will be interesting to learn how abnormalities in ion transport by CF airway epithelia affect the composition of airway surface fluid. This technique may provide a useful adjunct for testing potential pharmacological and genetic therapeutic interventions for CF epithelia.

\section{Acknowledgments}

We thank Phil Karp, Elizabeth Burton, and Corinne Conner for excellent technical assistance. We especially appreciate the extensive discussions with Dr. John B. Stokes III, as well as the use of his flame photometer.

This work was supported in part by the March of Dimes Birth Defects Foundation (Research Award \#1-FY91-0176); the National Heart, Lung, and Blood Institute (HL42385); and the Cystic Fibrosis Foundation. J. J. Smith was supported by the Parker B. Francis Foundation (Fellowship in Pulmonary Research) during part of the work on this project. M. J. Welsh is an Investigator of the Howard Hughes Medical Institute.

\section{References}

1. Welsh, M. J. 1987. Electrolyte transport by airway epithelia. Physiol. Rev. 67:1143-1184. 
2. Yoneda, K. 1976. Mucous blanket of rat bronchus. Am. Rev. Respir. Dis. 114:837-842.

3. Sleigh, M. A., J. R. Blake, and N. Liron. 1988. The propulsion of mucus by cilia. Am. Rev. Respir. Dis. 137:726-741.

4. Quinton, P. M. 1990. Cystic fibrosis: a disease in electrolyte transport. FASEB (Fed. Am. Soc. Exp. Biol.) J. 4:2709-2717.

5. Adams, G. K., E. F. Aharanson, M. J. Reasor, and D. F. Proctor. 1979. Collection of normal canine tracheobronchial secretions. J. Appl. Physiol. 40:247-249.

6. Boat, T. P., and P. W. Cheng. 1980. Biochemistry of airway mucus secretions. Fed. Proc. 39:3067-3074.

7. Chernick, W. S., and G. J. Barbero. 1959. Composition of tracheobronchia secretions in cystic fibrosis of the pancreas and bronchiectasis. Pediatrics. 24:739-745.

8. Matthews, L. W., S. Spector, J. Lemm, and J. L. Potter. 1968. Studies on pulmonary secretions. Am. Rev. Respir. Dis. 88:199-204.

9. Boucher, R. C., M. J. Stutts, P. A. Bromberg, and J. T. Gatzy. 1981. Regional differences in airway surface liquid composition. J. Appl. Physiol. Respir. Environ. Exercise Physiol. 50:613-620.

10. Mentz, W. M., J. B. Brown, M. Friedman, M. J. Stutts, J. T. Gatzy, and R. C. Boucher. 1986. Deposition, clearance, and effects of aerosolized amiloride in sheep airways. Am. Rev. Respir. Dis. 134:938-943.

11. Joris, L., and P. M. Quinton. 1987. Concentration of elements in airway surface fluid. Med. Sci. Res. 15:855-856.

12. Boucher, R. C., M. J. Stutts, M. R. Knowles, L. Cantley, and J. T. Gatzy. 1986. $\mathrm{Na}^{+}$transport in cystic fibrosis respiratory epithelia. Abnormal basal rate and response to adenylate cyclase activation. J. Clin. Invest. 78:1245-1252.

13. Knowles, M. R., N. L. Church, W. E. Waltner, J. R. Yankaskas, P. Gilligan, M. King, L. J. Edwards, R. W. Helms, and R. C. Boucher. 1990. A pilot study of aerosolized amiloride for the treatment of lung disease in cystic fibrosis. N. Engl. J. Med. 322:1189-1194.

14. App, E. M., M. King, R. Helfesrieder, D. Köhler, and H. Matthys. 1990. Acute and long-term amiloride inhalation in cystic fibrosis lung disease. Am. Rev. Respir. Dis. 141:605-612.

15. Coleman, D. L., I. K. Tuet, and J. H. Widdicombe. 1984. Electrical properties of dog epithelial cells grown in monolayer culture. Am. J. Physiol. 246(Cell Physiol. 15):C355-C359.

16. Welsh, M. J. 1985. Ion transport by primary cultures of canine tracheal epithelium: methodology, morphology, and electrophysiology. J. Membr. Biol. 88:149-163.

17. Wu, R., J. Yankaskas, E. Cheng, M. R. Knowles, and R. Boucher. 1985. Growth and differentiation of human nasal epithelial cells in culture. Am. Rev. Respir. Dis. 132:311-320.

18. Mangoo-Karim, R., M. E. Uchic, M. Grant, W. A. Shumate, J. P. Calvet, C. H. Park, and J. J. Grantham. 1989. Renal epithelial fluid secretion and cyst growth: the role of cyclic AMP. FASEB (Fed. Am. Soc. Exp. Biol.) J. 3:26292632.

19. Widdicombe, J. H., and M. J. Welsh. 1980. Ion transport by dog tracheal epithelium. Fed. Proc. 39:3062-3066.

20. Boucher, R. C., C. U. Cotton, J. T. Gatzy, M. R. Knowles, and J. R. Yankaskas. 1988. Evidence for reduced $\mathrm{Cl}^{-}$and increased $\mathrm{Na}^{+}$permeability in cystic fibrosis human primary cell cultures. J. Physiol. (Lond.). 405:77-103.

21. Al-Bazzaz, F. J. 1981. Role of cyclic AMP in regulation of chloride secretion by canine tracheal mucosa. Am. Rev. Respir. Dis. 123:295-298.

22. Smith, P. L., M. J. Welsh, J. S. Stoff, and R. A. Frizzell. 1982. Chloride secretion by canine tracheal epithelium: I. Role of intracellular cAMP levels. $J$. Membr. Biol. 70:217-226.

23. Widdicombe, J. H. 1986. Cystic fibrosis and $\beta$-adrenergic response of airway epithelial cell cultures. Am. J. Physiol. 251 (Regulatory Integrative Comp. Physiol. 20):R818-R822.

24. Knowles, M. R., M. J. Stutts, J. R. Yankaskas, J. T. Gatzy, and R. C. Boucher. 1986. Abnormal respiratory epithelial ion transport in cystic fibrosis. Clin. Chest Med. 7:285-297.

25. Doucet, A., and S. Marsey. 1987. Characterization of K-ATPase activity in distal nephron: stimulation by potassium depletion. Am. J. Physiol. 253(Renal Fluid Electrolyte Physiol. 22):F418-F423.

26. Hersey, S. J., L. Steiner, J. Mendlein, E. Rabon, and G. Sachs. 1988. SCH 28080 prevents omeprazole inhibition of the gastric $\mathrm{H}^{+} / \mathrm{K}^{+}$-ATPase. Biochim. Biophys. Acta. 956:49-57.

27. Kaminski, J. J., B. Wallmark, C. Briving, and B.-M. Andersson. 1991. Antiulcer agents. 5 . Inhibition of gastrin $\mathrm{H}^{+} / \mathrm{K}^{+}$-ATPase by substituted imidazo $[1,2-a]$ pyridines and related analogues and its implication in modeling the high affinity potassium ion binding site of the gastric proton pump enzyme. $J$. Med. Chem. 34:533-541.

28. Planelles, G., T. Anagnostopoulos, L. Cheval, and A. Doucet. 1991. Bio- chemical and functional characterization of $\mathrm{H}^{+}-\mathrm{K}^{+}$-ATPase in distal amphibian nephron. Am. J. Physiol. 260(Renal Fluid Electrolyte Physiol. 29): F806-F812.

29. Welsh, M. J. 1984. Energetics of chloride secretion in canine tracheal epithelium. J. Clin. Invest. 74:262-268.

30. Olver, R. E., B. Davis, M. G. Marin, and J. A. Nadel. 1975. Active transport of $\mathrm{Na}^{+}$and $\mathrm{Cl}^{-}$across the canine tracheal epithelium in vitro. Am. Rev. Respir. Dis. 112:811-815.

31. Widdicombe, J. H., I. F. Ueki, I. Bruderman, and J. A. Nadel. 1979. The effects of sodium substitution and ouabain on ion transport by dog tracheal epithelium. Am. Rev. Respir. Dis. 120:385-392.

32. Al-Bazzaz, F. J., and Q. Al-Awqati. 1979. Interaction between sodium and chloride transport in canine tracheal mucosa. J. Appl. Physiol. Respir. Environ. Exercise Physiol. 46:111-119.

33. Knowles, M., G. Murray, J. Shallal, F. Askin, V. Ranga, J. Gatzy, and R. Boucher. 1984. Bioelectric properties and ion flow across excised human bronchi. J. Appl. Physiol. Respir. Environ. Exercise Physiol. 56:868-877.

34. Cullen, J. J., and M. J. Welsh. 1987. Regulation of sodium absorption by canine tracheal epithelium. J. Clin. Invest. 79:73-79.

35. Cott, G. R., S. Kazuhiro, and R. J. Mason. 1986. Stimulation of net active ion transport across type II cell monolayers. Am. J. Physiol. 250(Cell Physiol. 19):C222-C227.

36. Cheek, J. M., K.-J. Kim, and E. D. Crandall. 1989. Tight monolayers of rat alveolar epithelial cells: bioelectric properties and active sodium transport. Am. J. Physiol. 256(Cell Physiol. 25):C688-C693.

37. Olver, R. E., C. A. Ramsdem, L. B. Strang, et al. 1986. The role of amiloride-blockade sodium transport in adrenaline-induced lung liquid reabsorption in the fetal lamb. J. Physiol. (Lond.). 376:321-340.

38. Schlatter, E., and J. A. Schafer. 1987. Electrophysiological studies in principal cells of rat cortical collecting tubules: ADH increases the apical membrane $\mathrm{Na}^{+}$-conductance. Pfluegers Arch. Eur. J. Physiol. 409:81-92.

39. Marunaka, Y., and D. C. Eaton. 1991. Effects of vasopressin and cAMP on single amiloride-blockable Na channels. Am. J. Physiol. 260(Cell Physiol. 29):C1071-C1084.

40. Lester, D. S., C. Asher, and H. Garty. 1988. Characterization of cAMP-induced activation of epithelial sodium channels. Am. J. Physiol. 254(Cell Physiol. 23):C802-C808.

41. Johnsen, A. H., and R. Nielsen. 1982. Enhanced sensitivity to stimulation of sodium transport and cyclic AMP by antidiuretic hormone after $\mathrm{Ca}^{2+}$ depletion of isolated frog skin epithelium. J. Membr. Biol. 69:137-143.

42. Welsh, M. J., P. L. Smith, and R. A. Frizzell. 1982. Chloride secretion by canine tracheal epithelium: II. The cellular electrical potential profile. J. Membr. Biol. 70:227-238.

43. Welsh, M. J., P. L. Smith, and R. A. Frizzell. 1983. Chloride secretion by canine tracheal epithelium: III. Membrane resistances and electromotive forces. J. Membr. Biol. 71:209-218.

44. Cotton, C. U., M. J. Stutts, M. R. Knowles, J. T. Gatzy, and R. C. Boucher. 1987. Abnormal apical cell membrane in cystic fibrosis respiratory epithelium. An in vitro electrophysiologic analysis. J. Clin. Invest. 79:80-85.

45. Smith, J. J., and M. J. Welsh. 1992. cAMP stimulates $\mathrm{HCO}_{3}^{-}$secretion across normal but not cystic fibrosis airway epithelia. J. Clin. Invest. 89:11451153.

46. Dean, J. A., editor. 1973. Lange's Handbook of Chemistry. 11th ed. New York: McGraw-Hill Book Co. New York. 5-30.

47. Guerrin, F., C. Voisin, V. Macquet, H. Robin, and P. Lequien. 1971. Apport de la pH metrie bronchique in situ. Progr. Respir. Res. 6:372-383.

48. Mentz, W. M., M. R. Knowles, J. B. Brown, J. T. Gatzy, and R. C. Boucher. 1984. Measurement of airway surface liquid (ASL) composition of normal human subjects. Am. Rev. Respir. Dis. 129:315a. (Abstr.)

49. Kyle, H., J. P. T. Ward, and J. G. Widdicombe. 1990. Control of pH of airway surface liquid of the ferret trachea in vitro. J. Appl. Physiol. 68:135-140.

50. Nielson, D. W., J. Goerke, and J. A. Clements. 1981. Alveolar subphase pH in the lungs of anesthetized rabbits. Proc. Natl. Acad. Sci. USA. 78:71197123.

51. Adamson, T. M., R. D. H. Boyd, H. S. Platt, and L. B. Strang. 1969. Composition of alveolar liquid in the foetal lamb. J. Physiol. (Lond.). 204:159168.

52. Welsh, M. J., J. H. Widdicombe, and J. A. Nadel. 1980. Fluid transport across canine tracheal epithelium. J. Appl. Physiol. Respir. Environ. Exercise Physiol. 49:905-909.

53. Melon, J. 1968. Activité sécrétoire de la muqueuse nasale. Acta Oto Rhino-Laryngol. Belg. 22:5-244.

54. Robinson, N. P., H. Kyle, S. E. Webber, and J. G. Widdicombe. 1989. Electrolyte and other chemical concentrations in tracheal airway surface liquid and mucus. J. Appl. Physiol. 66:2129-2135. 